\title{
Resistência física de bainhas de plantas de arroz supridas com silício e infectadas por Rhizoctonia solani
}

\author{
Daniel Augusto Schurt ${ }^{1}$, Fabrício Ávila Rodrigues ${ }^{1}$, Ricardo Dutra Reis ${ }^{1}$, Wiler Ribas Moreira ${ }^{1}$, Naiara \\ Fernandes Abreu Souza ${ }^{1} \&$ Washington Azevedo Silva ${ }^{2}$
}

${ }^{1}$ Laboratório de Interação Planta-Patógeno, Departamento de Fitopatologia, Universidade Federal de Viçosa, 36570-000, Viçosa, MG, Brasil; ${ }^{2}$ Universidade Federal de São João Del Rei, Campus Sete Lagoas, Rodovia MG-424, Km 45, Cx. Postal 56, 35701-970, Sete Lagoas, MG, Brasil

Autor para correspondência: Fabrício A. Rodrigues, e-mail: fabricio@ufv.br

\begin{abstract}
RESUMO
Este trabalho objetivou associar a deposição de silício ( $\mathrm{Si}$ ) nas bainhas de plantas de arroz ao aumento da resistência física à infecção por Rhizoctonia solani. Plantas das cultivares suscetíveis BR-Irga 409 e Labelle foram cultivadas em solução nutritiva contendo (+Si) ou não (-Si) Si. A concentração de Si nas bainhas das plantas supridas com Si e inoculadas com R. solani aumentou significativamente em relação às plantas não supridas com Si reduzindo o comprimento relativo da lesão às 96 horas após inoculação (hai). Houve diferença significativa entre os tratamentos -Si e +Si quanto à força necessária para uma agulha metálica atravessar as bainhas às 48 e 72 hai. A maior resistência física às 24 hai deve-se ao fato de que $R$. solani estava crescendo sobre o tecido sem destruí-lo, o que pôde ser comprovado pela ausência de sintomas. Após esse período, a resistência diminuiu devido ao rápido crescimento de $R$. solani. Entretanto, nas bainhas de plantas supridas com Si, a força necessária para a agulha penetrar foi maior às 48 e 72 hai. A resistência das bainhas de plantas supridas com Si à infecção por $R$. solani pode ser explicada, em parte, pela maior resistência física decorrente da deposição desse elemento.

Palavras-chave: Oryza sativa, escleródios, queima das bainhas, punctura.
\end{abstract}

\begin{abstract}
Physical resistance of leaf sheaths of rice plants supplied with silicon and infected by Rhizoctonia solani

This study aimed to associate the silicon $(\mathrm{Si})$ deposition on sheaths of rice plants with an increase in physical resistance against infection by Rhizoctonia solani. Plants from the susceptible cultivars BR-Irga 409 and Labelle were grown in nutrient solution containing $(+\mathrm{Si})$ or not $(-\mathrm{Si}) \mathrm{Si}$. Si concentration on sheaths of plants supplied with $\mathrm{Si}$ and inoculated with $R$. solani significantly increased compared to plants non-supplied with $\mathrm{Si}$, reducing the relative lesion length at 96 hours after inoculation (hai). There were significant differences between $-\mathrm{Si}$ and $+\mathrm{Si}$ treatments for the force required of a metal needle to pass through the sheaths at 48 and 72 hai. The greater physical resistance at 24 hai was due to the fact that $R$. solani was growing on sheath tissue without destroying it, which could be proved by the absence of symptoms. After this period, the resistance decreased due to the rapid $R$. solani growth. However, on sheaths of plants supplied with $\mathrm{Si}$, the force required for the needle to penetrate was higher at 48 and 72 hai. The sheath resistance of plants supplied with $\mathrm{Si}$ to infection by $R$. solani can be explained partly by the greater physical resistance due to Si deposition.
\end{abstract}

Key words: Oryza sativa, puncture, sclerotium, sheath blight.

A queima das bainhas, causada por Rhizoctonia solani Kühn (Thanatephorus cucumeris (A. B. Frank) Donk) é uma das principais doenças fúngicas do arroz [Oryza sativa L.] em todo o mundo (Ou, 1985). Essa doença causa sérios prejuízos na produção do arroz cultivado em diversos estados brasileiros, devido, principalmente, ao uso de irrigação, rotação com a soja e condições climáticas favoráveis para a ocorrência de epidemias severas (Bedendo $\&$ Prabhu, 2005). Além disso, a produção de escleródios por $R$. solani dificulta o manejo da doença (Dath, 1990; Lee \& Rush, 1983). As plantas são infectadas quando os escleródios entram em contato com as bainhas, germinam e o micélio forma inúmeras almofadas de infecção na superfície delas (Dath, 1990), originando lesões circulares e/ou arredondadas de coloração acinzentada, com bordas marrom-escuras $(\mathrm{Ou}$,
1985). Ao coalescerem, as lesões causam seca parcial ou total das bainhas e das folhas, acamamento das plantas, maior porcentagem de glumas vazias e redução no número de perfilhos (Rush \& Lee, 1992).

O silício $(\mathrm{Si})$ aumenta a resistência do arroz a diversas doenças fúngicas, tais como brusone, manchaparda, queima das bainhas e escaldadura (Datnoff et al., 2007). Plantas de arroz de diferentes cultivares supridas com Si e inoculadas em diferentes estádios de crescimento apresentaram redução na intensidade da queima das bainhas (Rodrigues et al., 2001, 2003ab). A concentração foliar de Si em arroz pode chegar a $10 \mathrm{dag} / \mathrm{kg}$ (Dallagnol et al., 2009), sendo superior à concentração de alguns macronutrientes como o nitrogênio, o fósforo e o potássio (Ma \& Takahashi, 2002). O Si é absorvido pelas raízes das plantas na forma 
de ácido monosilícico, sendo transportado, passivamente, via fluxo da transpiração, e depositado abaixo da cutícula, formando uma dupla camada sílica-cutícula (Sangster et al., 2001; Yoshida et al., 1962). De acordo com Kim et al. (2002), essa dupla camada atrasou a penetração de Pyricularia grisea nas folhas de arroz (Kim et al., 2002). Ito \& Sakamoto (1939), ao mensurarem a resistência à punctura de folhas de plantas de arroz supridas com Si e inoculadas com $P$. grisea, utilizando uma balança de torção com uma fina agulha de metal que perfurava o tecido e media a força utilizada para tal, observaram que, para as folhas de plantas supridas com $\mathrm{Si}$ e inoculadas com $P$. grisea, a resistência à punctura foi maior, ao contrário das plantas não supridas com esse elemento.

Considerando a importância do Si para a resistência do arroz à queima das bainhas, este trabalho objetivou associar a deposição desse elemento na bainha com o aumento na resistência física à infecção por $R$. solani.

Sementes de arroz das cultivares BR-Irga 409 e Labelle, suscetíveis a $R$. solani, foram desinfestadas em hipoclorito de sódio $10 \%(\mathrm{v} / \mathrm{v})$ por $2 \mathrm{~min}$, lavadas em água destilada por $3 \mathrm{~min}$, e colocadas para germinar em papel germiteste umedecido. Os rolos de papel germiteste foram colocados em câmara de germinação a $25^{\circ} \mathrm{C}$ por seis dias. As plântulas foram cultivadas em vasos plásticos com solução nutritiva diluída pela metade da concentração final por sete dias. Após esse período, as plantas foram transferidas para vasos plásticos contendo $5 \mathrm{~L}$ de solução nutritiva de Hoagland \& Arnon (1950), com algumas modificações, e constituída de $1 \mathrm{mM} \mathrm{KNO}_{3} ; 0,25 \mathrm{mM} \mathrm{NH}_{4} \mathrm{H}_{2} \mathrm{PO}_{4} ; 0,1 \mathrm{mM}$ $\mathrm{NH}_{4} \mathrm{Cl} ; 0,5 \mathrm{mM} \mathrm{MgSO}{ }_{4} \cdot 7 \mathrm{H}_{2} \mathrm{O} ; 1 \mathrm{mM} \mathrm{Ca}\left(\mathrm{NO}_{3}\right)_{2} \cdot 4 \mathrm{H}_{2} \mathrm{O} ; 0,3$ $\mu \mathrm{M} \mathrm{CuSO}_{4} .5 \mathrm{H}_{2} \mathrm{O} ; 0,33 \mu \mathrm{M} \mathrm{ZnSO}_{4} \cdot 7 \mathrm{H}_{2} \mathrm{O} ; 11,5 \mu \mathrm{M} \mathrm{H}_{3} \mathrm{BO}_{3}$; $3,5 \mu \mathrm{M} \mathrm{MnCl} \cdot 4 \mathrm{H}_{2} \mathrm{O} ; 0,014 \mu \mathrm{M}\left(\mathrm{NH}_{4}\right)_{6} \mathrm{Mo}_{7} \mathrm{O}_{2} \cdot 4 \mathrm{H}_{2} \mathrm{O} ; 25$ $\mu \mathrm{M} \mathrm{Na}_{2}$ EDTA e $25 \mu \mathrm{M} \mathrm{FeSO}_{4} \cdot 7 \mathrm{H}_{2} \mathrm{O}$. O Si, fornecido como ácido monosilícico, foi obtido pela passagem do silicato de potássio através de resina de troca de cátions (Amberlite IR-120B, $\mathrm{H}^{+}$forma, Sigma-Aldrich, São Paulo) (Ma et al., 2002). As concentrações de Si utilizadas foram de 0 e 2 $\mathrm{mM}$. A solução nutritiva foi trocada a cada quatro dias e o $\mathrm{pH}$ foi verificado a cada dois dias e mantido na faixa de 5,5 a 6 .

As bainhas das plantas foram inoculadas com R. solani aos 60 dias após o transplantio (estádio de máximo perfilhamento) para a solução nutritiva. Utilizouse o isolado de $R$. solani CNPAF $R s$-1 (AG-1 IA), fornecido pelo Dr. Anne Sitarama Prabhu (Embrapa Arroz e Feijão). Escleródios do fungo foram preservados em sílica gel. Após o crescimento do fungo em meio de cultura batata-dextroseágar (BDA), a partir dos escleródios, transferiram-se discos do meio contendo micélio para novas placas de Petri contendo BDA. Na superfície do meio de cultura contido em cada placa de Petri, colocaram-se pedaços de palito de dente de, aproximadamente, $1 \mathrm{~cm}$ de comprimento, que serviram como suporte para o crescimento do fungo. Os pedaços de palito, previamente lavados em água quente para remover possíveis substâncias tóxicas, foram colocados em frascos contendo BDA e autoclavados por 20 min (Rodrigues et al., 2001). As placas contendo micélio crescendo sobre e também no interior dos palitos permaneceram em câmara de crescimento $\left(25^{\circ} \mathrm{C}\right.$, fotoperíodo de $12 \mathrm{~h}$ luz/escuro $)$ por cinco dias. A segunda bainha do colmo principal de cada planta foi inoculada trespassando-se a mesma com auxílio de uma pinça estéril, um pedaço de palito colonizado pelo fungo. As bainhas inoculadas foram amarradas aos perfilhos das plantas com fitilhos. Imediatamente após a inoculação, as plantas foram transferidas para câmara de nevoeiro $\left(25 \pm 2^{\circ} \mathrm{C}\right.$ e umidade relativa de $\left.90 \pm 5 \%\right)$. Avaliou-se o comprimento da lesão em cada bainha inoculada às 24 , 48, 72 e 96 horas após inoculação (hai), com auxílio de um paquímetro digital. O comprimento relativo da lesão (CRL) foi calculado dividindo-se o comprimento da lesão pelo comprimento da bainha $\times 100$. O comprimento das bainhas foi padronizado em $15 \mathrm{~cm}$.

Quinze pedaços de bainhas ( $3 \mathrm{~cm}$ de comprimento) foram coletados das plantas das repetições de cada tratamento e fixadas sobre uma base de aço inoxidável na máquina universal de ensaios e testes da marca Instron série 3367 (Instron, Grove City, PA, EUA) com fita adesiva. As bainhas foram imediatamente submetidas à introdução de uma agulha metálica hipodérmica fina com $30 \mu \mathrm{M}$ de diâmetro. $\mathrm{O}$ teste de compressão foi realizado de modo que a agulha se movesse perpendicularmente (velocidade inicial de $1 \mathrm{~mm} / \mathrm{min}$ com máximo de 50 $\mathrm{mm} / \mathrm{min}$ ) sobre a bainha. A força exercida pela agulha foi medida em Newton $(\mathrm{N})$. A agulha foi introduzida da parte abaxial para a parte adaxial de cada pedaço de bainha. Após a introdução da agulha e a medição da resistência, os pedaços de bainhas foram colocados em tubos de microcentrífuga contendo $2 \mathrm{~mL}$ de álcool a $70 \%$, clareadas (Rodrigues et al., 2005), montadas em lâminas de vidro e observadas no microscópio de luz (Carl Zeiss, Axio Imager 1A). A solução de álcool foi trocada diariamente até a completa remoção da clorofila. Apenas os valores da resistência à punctura obtidos das bainhas nas quais a agulha não perfurou as nervuras foram utilizados na análise estatística.

As bainhas das plantas foram coletadas após o término do experimento, secadas em estufa a $65^{\circ} \mathrm{C}$ até atingirem peso constante e moídas em moinho tipo Wiley para determinação da concentração de $\mathrm{Si}$, de acordo com Korndörfer et al. (2004).

$\mathrm{O}$ experimento foi instalado em delineamento inteiramente casualizado em esquema fatorial $2 \times 2 \mathrm{com}$ 15 repetições. Os fatores estudados foram duas cultivares de arroz e presença (+Si) ou ausência (-Si) de Si na solução nutritiva. Cada repetição foi constituída de um vaso plástico contendo uma planta de arroz, da qual apenas a bainha do colmo principal foi inoculada com $R$. solani. Os dados da concentração de Si na bainha foram submetidos à ANOVA e as médias dos tratamentos comparadas pelo teste de Tukey $(P \leq 0,05)$, utilizando-se o programa SAS 9.0 (SAS Institute Inc., Cary, NC, EUA). Os dados de CRL e resistência física 
(força $\mathrm{N}$ ) entre os tratamentos $-\mathrm{Si}$ e $+\mathrm{Si}$, para cada época de avaliação foram comparados pelo teste- $t(P \leq 0,05)$.

Houve efeito significativo apenas do fator doses de Si para a concentração de Si nas bainhas. A concentração de Si nas bainhas das plantas supridas com Si (2,50 dag $/ \mathrm{kg})$ aumentou significativamente em $75 \%$ em relação às plantas não supridas com esse elemento $(0,63 \mathrm{dag} / \mathrm{kg})$.

Não foram observadas lesões nas bainhas das plantas às 24 hai, mas observou-se a presença de hifas de $R$. solani sobre elas. Para ambas as cultivares, não houve diferença significativa entre os tratamentos - $\mathrm{Si}$ e $+\mathrm{Si}$, tanto às 48 quanto às 72 hai (Figura $1 \mathrm{~A} \mathrm{e} \mathrm{B}$ ). Às 96 hai, houve decréscimo significativo de 18 e $21 \%$ no CRL nas bainhas das plantas das cultivares BR-Irga 409 e Labelle supridas com $\mathrm{Si}$, respectivamente, em relação às bainhas das plantas dessas cultivares não supridas com Si (Figura 1A e B). Os dados obtidos no presente estudo estão de acordo com os obtidos por Rodrigues et al. (2001, 2003b), os quais mostraram o potencial de Si em reduzir a intensidade da queima das bainhas em diferentes cultivares de arroz, incluindo BR-Irga 409 e Labelle. Além disso, Rodrigues et al. (2001) ressaltaram que a resistência do arroz à queima das bainhas foi dependente do nível de resistência basal de cada cultivar de arroz a $R$. solani. Tanto a cultivar BR-Irga 409 (Rodrigues et al., 2003ab) quanto a cultivar Labelle (Rodrigues et al., 2001) são suscetíveis à infecção por R. solani.

Com relação à força necessária para a agulha atravessar as bainhas das plantas, houve diferença significativa entre os tratamentos $-\mathrm{Si}$ e $+\mathrm{Si}$ somente às 48 e 72 hai (Figura 2A e B). A maior resistência das bainhas infectadas por $R$. solani à punctura deve ser atribuída a deposição de Si. Ito \& Sakamoto (1939) mensuraram a resistência de folhas de arroz à punctura e observaram maior resistência física em associação com menor tamanho das lesões nas folhas das plantas supridas com Si. Esses autores também observaram que a maior quantidade de células silicatadas na epiderme das folhas das plantas supridas com Si contribuiu para uma maior resistência à punctura. A maior resistência física das bainhas de arroz à punctura não necessariamente representa um impedimento à penetração por $R$. solani, pois o fungo é capaz de penetrar pelos estômatos localizados no interior das bainhas (Ou, 1985). De acordo com Ito \& Sakamoto (1939), a resistência de folhas de arroz à punctura aumentou com a idade da planta. Rodrigues et al. (2003b) relataram que plantas de arroz com 96 e 113 dias (estádios de emborrachamento e emissão de panícula, respectivamente) foram mais resistentes à queima das bainhas do que plantas com 45 dias de idade (estádio vegetativo). Além disso, os autores observaram um decréscimo na concentração de Si com o aumento da idade das plantas de arroz, ou seja, do estádio vegetativo até o de emissão de panícula. Possivelmente, o aumento da resistência das bainhas de folhas mais velhas à punctura esteja associado com a lignificação dos tecidos e não necessariamente com uma maior concentração de $\mathrm{Si}$,
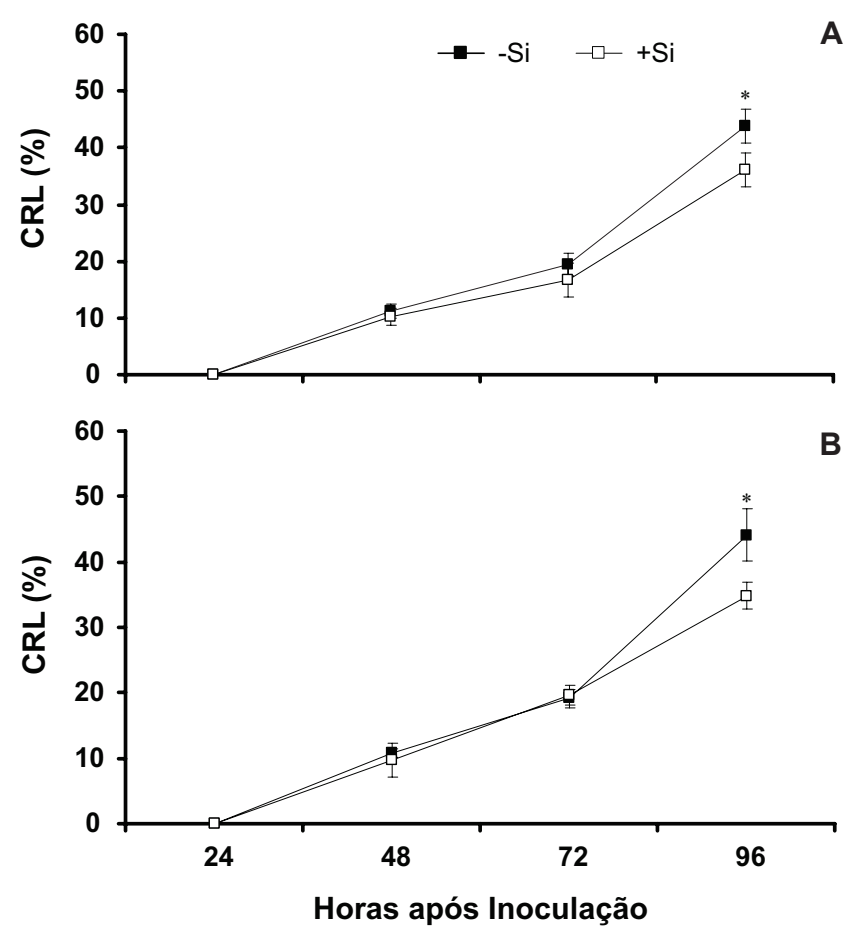

FIGURA 1 - Comprimento relativo da lesão (CRL) da queima das bainhas nas bainhas de plantas de arroz das cultivares BR-Irga 409 (A) e Labelle (B) cultivadas em solução nutritiva contendo (+Si) ou não (-Si) silício ( $\mathrm{Si}$ ) e inoculadas com Rhizoctonia solani. Médias dos tratamentos -Si e + Si para cada época de avaliação seguidas por asterisco diferem pelo teste-t $(\mathrm{P} \leq 0,05)$.

sabendo-se, todavia, que a lignificação é, de certa forma, aumentada em plantas supridas com Si (Rodrigues et al., 2005; Dallagnol et al., 2011).

A maior resistência (força medida em Newton) das bainhas das plantas à punctura às 24 hai (Figura 2A e B) deve-se, provavelmente, ao fato de $R$. solani ainda estar crescendo sobre o tecido da bainha sem destruí-lo, o que pode ser comprovado pela ausência de sintomas (Figura 1A e B). Após esse período, a resistência das bainhas diminuiu devido ao rápido crescimento do patógeno e à formação de inúmeras almofadas de infecção na sua superfície, causando morte rápida das células, em razão da ação de toxinas não específicas secretadas pelo fungo (Ou, 1985). Entretanto, nas bainhas obtidas das plantas supridas com $\mathrm{Si}$, a força necessária para a agulha penetrar foi maior às 48 e 72 hai. Estudos mostram que plantas de arroz supridas com $\mathrm{Si}$ são mais resistentes à brusone, devido à presença de células densamente silicatadas na epiderme (Ito \& Hayashi 1931; Suzuki, 1940) ou pela formação da dupla camada sílica-cutícula (Kim et al., 2002).

Os resultados do presente estudo permitem concluir que a resistência das bainhas das plantas de arroz supridas com $\mathrm{Si}$ à infecção por $R$. solani pode ser explicada, em parte, pela maior resistência física decorrente da deposição desse elemento. 


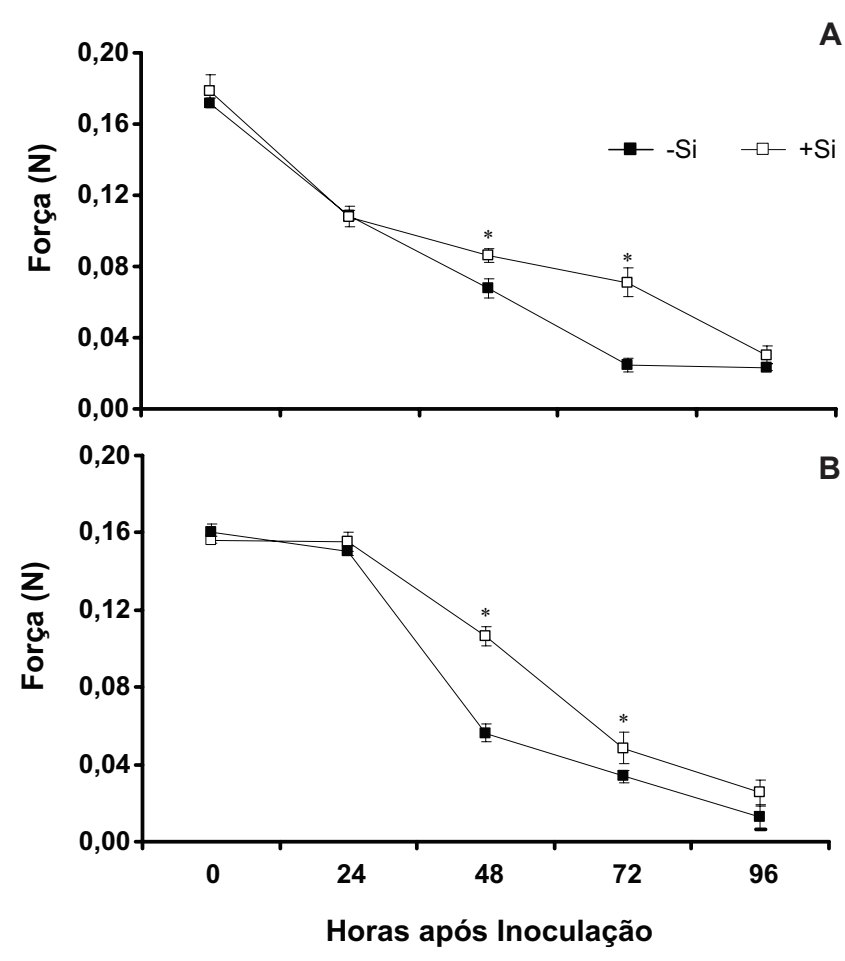

FIGURA 2 - Força (medida em Newton - N) necessária para uma agulha metálica atravessar a bainha de plantas de arroz das cultivares BR-Irga 409 (A) e Labelle (B) cultivadas em solução nutritiva contendo $(+\mathrm{Si})$ ou não $(-\mathrm{Si})$ silício $(\mathrm{Si})$ e inoculadas com Rhizoctonia solani. Médias dos tratamentos $-\mathrm{Si}$ e $+\mathrm{Si}$ para cada época de avaliação seguidas por asterisco diferem pelo teste-t $(\mathrm{P} \leq 0,05)$. O número de repetições por tratamento variou de $10 \mathrm{a}$ 12.

\section{AGRADECIMENTOS}

Ao Conselho Nacional de Desenvolvimento Científico e Tecnológico - CNPq, à Coordenação de Aperfeiçoamento de Pessoal de Nível Superior - CAPES, e à Fundação de Amparo à Pesquisa do Estado de Minas Gerais - FAPEMIG, pelos recursos financeiros. Ao CNPq, pela bolsa de produtividade em pesquisa concedida ao Prof. F. A. Rodrigues. À FAPEMIG, pela bolsa de doutorado concedida a D. A. Schurt. Ao Dr. Anne Sitarama Prabhu (Embrapa Arooz e Feijão), pelo fornecimento do isolado de R. solani e das sementes das cultivares de arroz. À Prof. ${ }^{\mathrm{a}}$ Nilda de Fátima Ferreira Soares (UFV/DTA), pelo uso da máquina universal de ensaios e testes.

\section{REFERÊNCIAS BIBLIOGRÁFICAS}

Bedendo IP, Prabhu AS (2005) Doenças do arroz. In: Kimati H, Amorim L, Rezende JAM, Bergamin Filho A, Camargo LEA (Eds.) Manual de fitopatologia - doenças das plantas cultivadas. V. 2. $4^{\text {a }}$ Ed. São Paulo SP. Editora Agrônomica Ceres. pp. 7990 .

Dallagnol LJ, Rodrigues FA, DaMatta FM, Mielli MVB, Pereira SC (2011). Deficiency in silicon uptake affects cytological, physiological, and biochemical events in the rice-Bipolaris oryzae interaction. Phytopathology 101:92-104.

Dallagnol LJ, Rodrigues FA, Mielli MVB, Ma JF, Datnoff LE (2009) Defective active silicon uptake affects some components of rice resistance to brown spot. Phytopathology 99:116-121.

Dath AP (1990) Sheath blight disease of rice and its management. New Delhi, India. Associated Publishing Company.

Datnoff LE, Rodrigues FA, Seebold KW (2007) Silicon and plant diseases. In: Datnoff LE, Elmer WH, Huber DM (Eds.) Mineral nutrition and plant diseases. St. Paul MN. APS Press. pp. 233-246.

Hoagland R, Arnon I (1950) The water culture method for growing plants without soil. Circular of the California Agricultural Experiment Station 347:1-32.

Ito S, Hayashi H (1931) On the relation of silica supply to rice blast. Journal Sapporo Society Agriculture Science 103:460461.

Ito S, Sakamoto M (1939) Studies on rice blast. Department of Botany, Faculty of Agriculture Report, Hokkaido University, Hokkaido, Japan. pp. 1939-1943.

Kim SG, Kim KW, Park EW, Choi D (2002) Silicon-induced cell wall fortification of rice leaves: A possible cellular mechanism of enhanced host resistance to blast. Phytopathology 92:10951103.

Korndörfer GH, Pereira HS, Nola A (2004) Análise de silício: solo, planta e fertilizante. Uberlândia MG. Grupo de Pesquisa em Silício/ICIAG/Universidade Federal de Uberlândia. (Boletim Técnico 1)

Lee FN, Rush MC (1983) Rice sheath blight: a major rice disease. Plant Disease 67:829-832.

Ma JF, Takahashi E (2002) Soil, fertilizer, and plant silicon research in Japan. Amsterdam, The Netherlands. Elsevier.

Ma JF, Tamai K, Ichii M, Wu GF (2002) A rice mutant defective in Si uptake. Plant Physiology 130:2111-2117.

Ou SH (1985) Rice diseases. $2^{\text {nd }}$ Ed. Kew, England. Commonwealth Mycological Institute.

Rodrigues FA, Datnoff LE, Korndörfer GH, Seebold KW, Rush MC (2001) Effect of silicon and host resistance on sheath blight development in rice. Plant Disease 85:827-832.

Rodrigues FA, Jurick WM, Datnoff LE, Jones JB, Rollins JA (2005) Silicon influences cytological and molecular events in compatible and incompatible rice-Magnaporthe grisea interactions. Physiological and Molecular Plant Pathology 66:144-159.

Rodrigues FA, Vale FXR, Datnoff LE, Prabhu AS, Korndörfer GH (2003a) Effect of rice growth stages and silicon on sheath blight development. Phytopathology 93:256-261.

Rodrigues FA, Vale FXR, Korndörfer GH, Prabhu AS, Datnoff LE, Oliveira AMA, Zambolim L (2003b). Influence of silicon on sheath blight of rice in Brazil. Crop Protection 22:23-29.

Rush MC, Lee FN (1992) Sheath blight. In: Webster RK, Gunnell PS (Eds.) Compendium of rice diseases. St. Paul MN. American Phytopathological Society. pp. 22-23.

Sangster AG, Hodson MJ, Tubb HJ (2001) Silicon deposition in higher plants. In Datnoff LE, Snyder GH, Korndörfer GH 
(Eds.) Silicon in agriculture. Amsterdam The Netherlands. Elsevier. pp. 85-114.

Suzuki H (1940) On the relationship between rice susceptibility and penetration into host plants. Ngyo Oyobi Engei 10:19992010 .
Yoshida S, Ohnishi Y, Kitagishi K (1962) Chemical forms, mobility and deposition of silicon in rice plant. Soil Science and Plant Nutrition 8:15-21.

TPP 490 - Recebido 17 Janeiro 2012 - Aceito 14 Maio 2012 Editor de Seção: Adalberto C. Café Filho 